\title{
Promoting the expansion and function of human corneal endothelial cells with an orbital adipose-derived stem cell-conditioned medium
}

Peng Sun ${ }^{1,2}$, Lin Shen ${ }^{1}$, Canwei Zhang ${ }^{1}$, Liqun Du ${ }^{1}$ and Xinyi Wu ${ }^{1 *}$

\begin{abstract}
Background: Corneal endothelial dysfunction causes severe impairment of vision. The only solution is corneal transplantation. However, this treatment is hampered by a worldwide shortage of donor corneas. New therapies may replace the conventional donor corneal transplantation alongside the developments in regenerative medicine and tissue engineering, but sufficient functional corneal endothelial cells (CECs) are essential. The aim of this study was to promote the expansion and function of human corneal endothelial cells (HCECs) in vitro and in vivo.

Methods: The phenotypes of human orbital adipose-derived stem cells (OASCs) were detected by flow cytometry and immunofluorescence. HCECs were isolated and cultured using a conditioned medium obtained from OASCs (OASC-CM) in vitro. Related cell markers of HCECs were analyzed by quantitative real-time polymerase chain reaction (qRT-PCR), Western blot, and immunofluorescence. The cell counting kit-8 (CCK-8) assay and the wound healing assay were performed to evaluate the proliferation ability of the cells. The cultured HCECs were then transplanted into rabbit and monkey corneal endothelial dysfunction models by cell injection.

Results: CD29, CD105, CD49e, CD166, and vimentin were highly expressed in cultured human OASCs. The CEC-relative markers zonula occludens- 1 (ZO-1), $\mathrm{Na}^{+} / \mathrm{K}^{+}$ATPase, N-cadherin, Col8a2, and SLC4A4 were expressed in HCECs cultured by OASC-CM. The HCECS were able to maintain polygonal cell morphology and good proliferative capacity. In animal experiments, corneal transparency was achieved after the injection of HCECs, which demonstrated the good repair capacity of the cells.

Conclusions: The proliferation abilities of the cells were significantly enhanced, and related functional markers were strongly positive, while HCEC morphology was maintained using OASC-CM. HCECs obtained some stem cell-like properties. This preclinical study confirmed the therapeutic ability of the HCECs in vivo. Our findings demonstrated that cultured HCECs with OASC-CM might be a promising source for research and clinical treatment.
\end{abstract}

Keywords: Corneal endothelial cell, Orbital adipose-derived stem cell, Conditioned medium, Corneal endothelial dysfunction, Regenerative medicine, Tissue engineering, Animal model, Cell therapy

\footnotetext{
*Correspondence: xywu8868@163.com

'Department of Ophthalmology, Qilu Hospital of Shandong University, Jinan,

Shandong 250012, People's Republic of China

Full list of author information is available at the end of the article
} 


\section{Background}

The corneal endothelium (CE) plays a very important role in maintaining cornea transparency via pump and barrier functions [1]. Corneal endothelial cells (CECs) have limited proliferative capacity in vivo [2-4]. Consequently, endothelial dysfunction causing severe vision loss is unavoidable when the number of endothelial cells reaches a critical cell density $\left(<1000\right.$ cells $\left./ \mathrm{mm}^{2}\right)$ due to a pathological status such as Fuchs endothelial corneal dystrophies, intraocular surgery, or trauma [1, 5]. Corneal transplantation (full corneal transplant or endothelial keratoplasty) is currently the only procedure for treating corneal endothelial dysfunction $[6,7]$. The treatment relies on a sufficient number of functional human corneal endothelial cells (HCECs). However, the worldwide shortage of transplantable donor corneal tissues remains a big problem [8]. Therefore, researchers are making great efforts using regenerative medicine and tissue engineering to overcome this problem [9]. Researchers have induced CEC-like cells from other types of cells and some of these cells have functions similar to CECs [10-12]. However, the proliferation ability and function of these cells is very limited. Thus there is a pressing need to find optimum protocols to expand HCECs in vitro since the procedures involved in the isolation and subsequent cultivation protocols greatly vary between laboratories [13-16].

In the present study, we first used conditioned medium (CM) obtained from human orbital adipose-derived stem cells (OASCs; OASC-CM) when cultivating HCECs. The cells were then investigated by proliferation assay in a preclinical study. Our findings showed that HCECs could maintain quite a good proliferative and cell-based therapeutic capacity even after 10 passages. These studies indicated that more useful cells should be available for the research into HCECs and clinical cell-based therapy for corneal endothelial dysfunction in the future.

\section{Methods}

\section{Animals}

Thirty-five New Zealand white rabbits weighing 2.0-4.0 $\mathrm{kg}$ (Xilingjiao Experimental Animal Breeding Center, Jinan, Shandong Province, China) and six rhesus monkeys weighing $3.0-4.0 \mathrm{~kg}$ (3 to 5 years of age; Hongli Medical Animal Experimental Research Center, Jinan, Shandong Province, China) were used for animal experiments.

\section{Isolation and primary culture of OASCs and HCECs}

Redundant orbital adipose tissues were collected from 15 patients aged between 23 and 65 (45.3 \pm 9.8) years following blepharoplastic surgeries. The OASCs were cultivated as previously described with slight modification $[17,18]$. Briefly, the orbital adipose tissues were repeatedly washed with phosphate-buffered saline (PBS).
The tissues were then fragmented with surgical scissors and suspended in $0.1 \%$ collagenase type I (Sigma) at $37{ }^{\circ} \mathrm{C}$ with gentle stirring. After $2-4 \mathrm{~h}$ digestion, fragmented tissues were re-suspended in Dulbecco's modified Eagle's medium low glucose (DMEM-LG) containing 10\% fetal bovine serum (FBS) for $5 \mathrm{~min}$ at room temperature (RT) and then filtered through a $70-\mu \mathrm{m}$ strainer. The fluid was washed with PBS and centrifuged twice for $5 \mathrm{~min}$ at 1200 rpm at RT. Cell suspensions were plated in T-25 flasks (Corning) in DMEM-LG supplemented with 10\% FBS (Gibco) and 10\% penicillin-streptomycin (Sigma), and incubated at $37{ }^{\circ} \mathrm{C}$ in $5 \% \mathrm{CO}_{2}$. After 2-4 days, nonadherent cells were removed, and adherent cells continued to be cultured until they reached confluence. The OASCs at passages 3 through 8 were used for experiments.

HCECs were obtained from discarded corneal-scleral rings after penetrating keratoplasty $(\mathrm{PK})$ and from the Eye Tissue Bank of Shandong Province, China. The age of donors ranged from 15 to 78 years $(n=10)$. Cells were cultured in accordance with previously published methods with some modification [13]. Briefly, after corneas were washed three times with M199 (Hyclone), the Descemet's membranes (DM) containing HCECs were stripped and incubated in basal culture medium (BM) overnight at $37{ }^{\circ} \mathrm{C}$ in $5 \% \mathrm{CO}_{2}$ for stabilization, followed by digestion with $1 \mathrm{mg} / \mathrm{mL}$ collagenase type I (Sigma) for 1-2 h. The HCECs were re-suspended and seeded in one well of a 12-well plate coated with FNC Coating Mix (Usbio). The cells were cultured in BM (BMHCECs) as the control group and in BM containing 10\% OASC-CM (CM-HCECs) as the experimental group. The BM was composed of Opti-MEM-I (Gibco), 8\% FBS, $5 \mathrm{ng} / \mathrm{mL}$ human epidermal growth factor (hEGF; PeproTech), $20 \mu \mathrm{g} / \mathrm{mL}$ ascorbic acid (Sigma), $200 \mathrm{mg} / \mathrm{L}$ calcium chloride, $0.08 \%$ chondroitin sulfate, and $50 \mu \mathrm{g} /$ $\mathrm{mL}$ penicillin-streptomycin [19].

\section{Flow cytometry}

Related cell markers of OASCs were analyzed by flow cytometry. The dissociated cells were incubated with fluorescein isothiocyanate (FITC) mouse anti-human CD29, phycoerythrin (PE) mouse anti-human CD34, PE mouse anti-human CD18, FITC mouse anti-human CD49e, PE mouse anti-human CD166, allophycocyanin (APC) mouse anti-human CD133, PE mouse antihuman CD45, and APC mouse anti-human CD105 (BD Biosciences) respectively at $4{ }^{\circ} \mathrm{C}$ for $30 \mathrm{~min}$, washed, and resuspended with PBS. The cells then underwent flow cytometry using the BD FACS Calibur. Analysis was performed using the Flow-Jo program (Treestar, USA).

\section{Preparation of OASC-CM}

OASCs were washed three times with PBS when they were at $60-80 \%$ confluence and the medium was replaced 
with basal growth medium. The OASCs were kept for an additional 12-24 h. The medium was then collected and filtered $(0.22 \mu \mathrm{m})$ and stored at $-80{ }^{\circ} \mathrm{C}$ to preserve the biological activity.

\section{Cell proliferation with a cell counting kit-8 (CCK-8) assay} Cell viability was measured using a commercial CCK-8 assay kit (BestBio Science, Shanghai, China) according to the manufacturer's protocol. Cells $\left(7 \times 10^{3}\right.$ cells per well $)$ were placed in 96-well plates with BM overnight at $37^{\circ}$ $\mathrm{C}$ in $5 \% \mathrm{CO}_{2}$. The $\mathrm{BM}$ was then removed. Cells were cultured in medium with different concentrations of OASC-CM for $24 \mathrm{~h}$ at $37{ }^{\circ} \mathrm{C}$ in $5 \% \mathrm{CO}_{2}$. CCK-8 solution $(10 \mu \mathrm{l})$ was added to each well, and cells were incubated at $37^{\circ} \mathrm{C}$ for $2.5 \mathrm{~h}$. The absorbance at $450 \mathrm{~nm}$ was measured using a multimode reader (MD).

\section{Immunofluorescence}

Cell or tissue sections were fixed with $4 \%$ paraformaldehyde for $15 \mathrm{~min}$ and incubated in $0.5 \%$ Triton X-100 for $10 \mathrm{~min}$ and $5 \%$ goat serum for $30 \mathrm{~min}$. Primary antibodies were mouse anti- $\mathrm{N}$-cadherin (1:100; Abcam), mouse anti- $\mathrm{Na}^{+} / \mathrm{K}^{+}$ATPase $\alpha-1$ (1:200; Millipore), rabbit anti-zonula occludens-1 (ZO-1; 1:100; Santa Cruz), mouse anti-human nuclei (1:100; Millipore), and rabbit anti-vimentin (1:200; Abcam). Cells were incubated with the primary antibodies overnight at $4{ }^{\circ} \mathrm{C}$. Secondary antibodies (1:100; all obtained from Beijing Zhongshan Technologies) coupled to FITC or TRITC were then applied for detection. Subsequently, the cells were stained with DAPI to visualize the nuclei. In negative controls, primary antibodies were substituted by PBS. Fluorescence was observed using a fluorescent microscope.

\section{Western blotting}

The total protein of HCECs was extracted using 1\% radioimmunoprecipitation assay lysis buffer (Beyotime) and quantified with the bicinchoninic acid protein assay kit (Beyotime). The protein was loaded onto a $10 \%$ sodium dodecyl sulfate-polyacrylamide electrophoresis gel, electrophoresed, and then transferred to a polyvinylidene difluoride membrane (Millipore). Membranes were blocked with $5 \%$ nonfat dried milk at room temperature for $2 \mathrm{~h}$, washed three times with TBST, and incubated with the primary antibody against rabbit anti- $\mathrm{Na}^{+} / \mathrm{K}^{+}$ ATPase $\alpha 1$ (1:100; CST), rabbit anti-ZO-1 (1:1000, CST), and GAPDH (1:1000; Beijing Zhongshan) overnight at 4 ${ }^{\circ} \mathrm{C}$. After immunoblotting with secondary antibodies (1:5000; Beyotime) at room temperature for $1 \mathrm{~h}$, the protein was detected with an enhanced chemiluminescent reagent (Millipore).

\section{Quantitative real-time reverse transcription polymerase} chain (qRT-PCR) reaction

The total RNA was extracted from HCECs using Trizol Reagent (Invitrogen) according to the manufacturer's protocol. A 1- $\mu$ g sample of total RNA was reversetranscribed to cDNA (complimentary DNA) with the ReverTra Ace kit (Toyobo). PCR analysis was performed using the SYBR Green enzyme mixture (Toyobo) and the Applied Roche 480 Real-Time PCR system according to the manufacturer's protocol. Primers used in the PCR are described in Table 1.

\section{Wound healing assay}

A wound healing assay was used to the compare cell migration and repair capacity of HCECs of different passages. HCECs were cultured in six-well plates in BM or CM. Linear wounds were created by scraping confluent cell monolayers with the tips of sterile pipettes. The detached cells were rinsed away with PBS after the scratch and the remaining HCECs were cultivated with medium. Phase-contrast pictures of the wound recovery were taken at $0,3,6,9$, and $12 \mathrm{~h}$. The remaining wound area was measured using Image J software.

\section{Injection of HCECs into a rabbit corneal endothelial dysfunction model}

Cell injection was performed to evaluate the cell-based therapy of HCECs. The cells were labeled by carboxyfluorescein diacetate succinimdyl ester (CFSE; Gene Copoeia) according to the manufacturer's protocol. Thirty-five rabbits were randomly divided into three groups: the CM-HCEC group, the BM-HCEC group, and the control group. The rabbits were intravenously anesthetized with $3 \%$ pentobarbital sodium and topically with oxybuprocaine hydrochloride. The corneal endothelial dysfunction model was created according to a previous method with slight modification [20, 21] (Additional file 1: Figure S1A and C). A modified irrigator needle (Shandong Weigao) was used to completely

Table 1 List of primers for polymerase chain reaction

\begin{tabular}{llll}
\hline Gene & Primer & Sequence $\left(5^{\prime}-3^{\prime}\right)$ & Size $(\mathrm{bp})$ \\
\hline $\mathrm{Na}^{+} / \mathrm{K}^{+}$ATPase a 1 & Forward & CTGTGGATGGAGCGTTCT & 112 \\
& Reverse & TTACAACGGCTGATAGCACCA & \\
Zo-1 & Forward & ATCCCTATCACCCAGCGTCA & 152 \\
& Reverse & TCTCCCACTCTGTCTCCAGG & \\
Col8a2 & Forward & CGACCTGAAAGCACGTCCAC & 85 \\
& Reverse & AGAGGCATTCAGTAGCAGCA & \\
SLC4A4 & Forward & TGATCGGGAGGTTCTTCTCT & 154 \\
& Reverse & GGACCGAAGGTGGATTTCTTG & \\
GAPDH & Forward & GCACCGTCAAGGCTGAGAAC & 138 \\
& Reverse & TGGTGAAGACGCCAGTGGA & \\
\hline & & &
\end{tabular}


scrape the CE from the DM (Additional file 1: Figure S1B). The aqueous humor was collected after anterior chamber irrigation; part of this was stained by trypan blue and hematoxylin to detect residual cells. The other part was placed in 96-well plates with culture medium at $37{ }^{\circ} \mathrm{C}$ in $5 \% \mathrm{CO}_{2}$ and observed daily by microscope.

Before cell injection, $100 \mu \mathrm{l}$ aqueous humor was extracted from the anterior chamber of the rabbit corneal endothelial dysfunction models. CFSE-labeled HCECs $\left(3.0 \times 10^{5}\right.$ cells $)$ were then suspended in $100 \mu \mathrm{l}$ OptiMEM-I and injected into the anterior chamber of the eyes using an insulin needle (BD). A peribulbar injection of triamcinolone acetonide and a subconjuctival injection of dexamethasone were given. After the injection, the operation eyes were kept in the face-down position for $5 \mathrm{~h}$ under general anesthesia. Tobramycin and dexamethasone drops were also given topically four times a day. Cultivated HCECs with BM at passage 3 (P3) were injected into the right eyes of five rabbits as the $\mathrm{BM}$ HCEC group. Cultivated HCECs with CM from passage 7 to passage 13 (P7, P9, P11, and P13) were injected into the right eyes of another 20 rabbits, respectively. These 20 rabbits were used as the CM-HCEC group. The left eyes of the rabbits were observed as the normal control. The left eyes of the remaining 10 rabbits in which the CE was mechanically removed without cell injection were used as the control group.

The corneal transparency and thickness were observed and photographed using slit-lamp microscopy (Topcon) and optical coherent tomography (OCT; Carl Zeiss). Images of CECs were taken and analyzed by confocal microscopy (HRT-II, Heidelberg Engineering) at days 1, 3, and 7.

\section{Histological examination of rabbit eyes}

Rabbits were sacrificed by an intravenous overdose of pentobarbital sodium 3 and 7 days after the transplantation. Postoperative eyes were removed and part of the cornea was embedded in Tissue-Tek optimum cutting temperature compound (Sakura) and sectioned into 5$\mu \mathrm{m}$ slices. The frozen slices were viewed under a microscope to detect the CFSE signal and were subjected to immunofluorescent staining. Part of the cornea was stained with Alizarin Red S and trypan blue to show cell survival and borders. Another part of the cornea was fixed in $4 \%$ formaldehyde and subjected to hematoxylin and eosin (H\&E) staining.

\section{Injection of HCECs into a monkey corneal endothelial dysfunction model}

Six monkeys were randomly divided into the CM-HCEC group $(n=4)$ and the control group $(n=2)$. Monkeys were placed under general anesthesia using ketamine hydrochloride. Monkey corneal endothelial pathological dysfunction models were created in the same manner as the rabbit models (Additional file 1: Figure S1A and D). In the preliminary experiments on the rabbits, we found that the corneal opacity could not be completely cured by BM-HCECs and CM-HCECs after P13, so we used P9 and P11 of CM-HCECs for cell injection.

Aqueous humor $(50 \mu \mathrm{l})$ was first extracted from the anterior chamber. CFSE-labeled HCECs $\left(2.7 \times 10^{5}\right.$ cells for each eye) were suspended in $50 \mu \mathrm{l}$ Opti-MEM-I and injected into the anterior chamber of four monkeys as the CM-HCEC group. The other two monkeys had the $\mathrm{CE}$ removed as the control group. The nonsurgical eyes of all monkeys were used as the normal group. A peribulbar injection of triamcinolone acetonide and a subconjuctival injection of dexamethasone were given. After the injection, the operation eyes were kept in a facedown position for $5 \mathrm{~h}$ under general anesthesia. Tobramycin and dexamethasone drops were given four times a day. The corneas were examined by a slit-lamp microscopy, AccuPen Handheld Tonometer (Accutome), OCT, confocal microscope, and noncontact specular microscopy (Topcon) at certain times after surgery. One monkey from the CM-HCEC group was euthanized at 2 months after the injection. Postoperative eyes were removed and part of the cornea was used to detect the CFSE signal and had immunofluorescent staining in the frozen section, and the other part was subjected to H\&E staining.

\section{Statistical analysis}

Data are presented as the means \pm SEM. The Student's $t$ test was used to examine differences between the two groups. Comparisons among three or more groups were made using one-way analysis of variance (ANOVA) and post-hoc analysis with the Bonferroni test. Differences were considered to be statistically significant at $p<0.05$.

\section{Results \\ Characterization of human OASCs}

In our study, human OASCs were plastic adherent, spindle-shaped, fibroblast-like cells (Fig. 1a and b). Surface immunophenotyping characterized by flow cytometry revealed that OASCs were negative for the bone marrow stromal cell marker CD18, the leukocyte common antigen $\mathrm{CD} 45$, the hematopoietic stem cell marker CD34, and CD133, and highly expressed CD29, CD105, CD49e, and CD166 (Fig. 1d), suggesting their endothelial and stem cell origin. Immunofluorescence staining showed that OASCs strongly expressed vimentin in the cell plasma which is a kind of intermediate filament protein found in normal HCECs (Fig. 1c) [22]. Cultured OASCs demonstrated similar morphology and phenotype before passage 10 . 


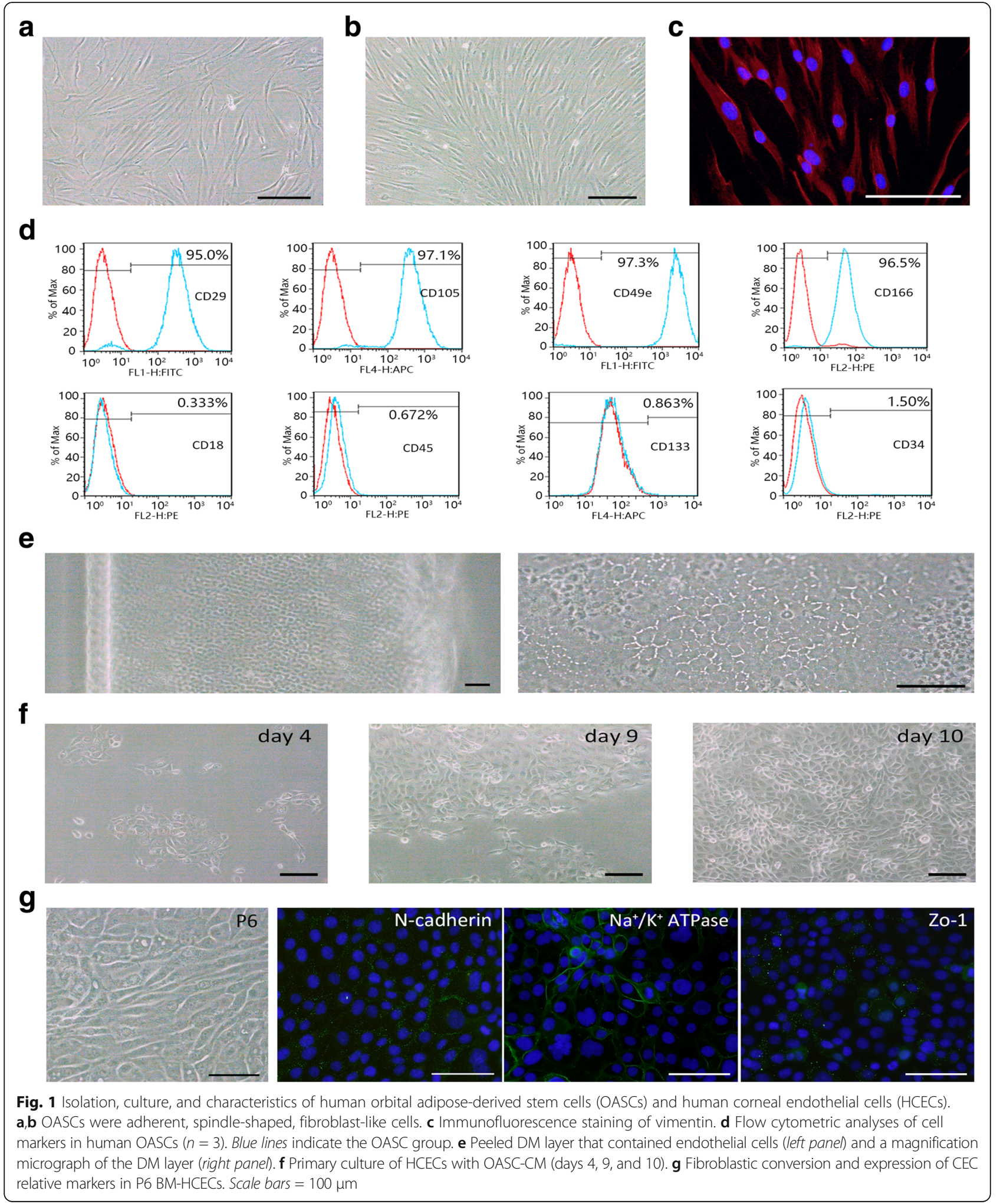

Effect of OASC-CM on the proliferation and expansion of HCECs in vitro

HCECs displayed hexagonal morphology on the DM in vivo (Fig. 1e). Under phase-contrast microscopy, the cultured primary HCECs passage 0 (P0) had a mosaic pattern (Fig. 1f), but after 4-5 passages cultured in BM HCECs began a fibroblastic change, became larger with vacuoles, and showed endothelial-to-mesenchymal transition (EMT). 
Expression levels of CEC-relative markers were also significantly decreased (Fig. 1g). We used OASC-CM and evaluated the effect on proliferation of HCECs. First, to test the suitable dilution, OASC-CM was added to the BM at final concentrations of $10 \%, 20 \% 30 \%, 50 \%, 80 \%$, or $100 \%$. The proliferative activity of the OASC-CM was then compared to that of the BM by CCK- 8 assay. The assay revealed that the proliferation of HCECs in the BM group was significantly lower than that in the $10-80 \%$ strength OASC-CM group. HCECs cultured in 10-80\% strength OASC-CM showed no difference in cell proliferation (Fig. 2a), and so we used the concentration of $10 \%$ OASC-CM in the following study.

\section{Effect of OASC-CM on the phenotype of HCECs}

The cells cultured in OASC-CM maintained the characteristic polygonal cell morphology and a contact-inhibited monolayer even after 10 passages (Fig. 2b). We then evaluated whether the cells still expressed the CEC-related functional proteins: the corneal endothelial differentiation marker N-cadherin [11, 23], sodium-potassium pump $\mathrm{Na}$ ${ }^{+} / \mathrm{K}^{+}$ATPase, tight junction protein ZO-1 [10], collagen type VIII (Col8a2), and solute carrier family 4 anion exchanger member 4 (SLC4A4) [24, 25]. Immunostaining of $\mathrm{N}$-cadherin, $\mathrm{Na}+/ \mathrm{K}+$ ATPase, and ZO-1 clearly outlined the intercellular adherent junction and cell borders of CMHCECs, while the expressions were very weak in P5 and P7 BM-HCECs (Fig. 3). PCR showed that CM-HCECs expressed high levels of the CEC markers (Fig. 4a-d). Western blot analysis also showed that P3, P5, and P7 CMHCECs expressed high protein levels of $\mathrm{Na}^{+} / \mathrm{K}^{+}$ATPase and $\mathrm{ZO}-1$ when similar passages were compared between BM-HCECs and CM-HCECs (Fig. 4e and f).

\section{Wound healing}

We compared four different passages of HCECs (P3 of BM-HCECs as the control and P9, P11, and P13 of CM-HCECs) in the wound healing assay. The wound closure rates were different. CM-HCECs (P9 and P11) demonstrated a faster healing rate (Fig. 2c and d). Although P13 CM-HCECs could not fully cover the wound within $12 \mathrm{~h}$, it still had a faster rate than P3 BM-HCECs (Fig. 2c and d).

\section{Cultivated HCEC injection in the rabbit model}

To evaluate the repair ability of CM-HCECs in vivo, we use the rabbit corneal endothelial dysfunction model by removing endothelial cells from the DM and anterior chamber after which we performed cell injection (Additional file 1: Figure S1A and C). No residual host CECs were found in the collected aqueous (Additional file 1: Figure S1E and F). Preliminary results showed that CM-HCECs (before P13) were successful in recovering transparency of the endothelially damaged corneas within 7 days, although anterior chamber exudation could be seen (Fig. 5a). The corneal thickness rapidly decreased after injection of CM-HCECs (Fig. 5b). The changes in the central corneal thickness (CCT) were compared between different groups (Fig. 6c). Confocal microscope images and Alizarin Red $\mathrm{S}$ staining confirmed coverage of polygonal cells on the DM in the CM-HCEC group (Fig. 5c and d). The cell density of different groups were 2898 cells $/ \mathrm{mm}^{2}$ (normal), 2008 cells/ $\mathrm{mm}^{2}$ (P9 CM-HCECs, day 3), 2654 cells $/ \mathrm{mm}^{2}$ (P9 CMHCECs, day 7). In contrast, the control group in which the endothelium was only scraped induced severe corneal opacity and edema (Fig. 5a). P3 BM-HCECs could also not make the cornea transparent. Obvious graft rejection was also observed (Fig. $5 \mathrm{a}$ and b). The same result occurred in the rabbit model injected with P5 BMHCECs (Additional file 2: Figure S2). There were no CECs detected in the BM-HCEC group and the control group by confocal microscopy and Alizarin Red S (Fig. 5c and d). Histological examination was performed after the euthanasia of the rabbits. The CFSE-labeled HCECs were detected by fluorescent microscope examination in the CM-HCEC group (Fig. 6a). H\&E staining showed that the HCECs tightly adhered to the DM of the cornea in a monolayer (Fig. 6b), whereas the DMs in the BM-HCEC and control groups were bare and no cells were detected (Fig. 6a and b).

\section{Cultivated HCEC injection in the primate model}

For further research we used a monkey corneal endothelial dysfunction model to study the cell repair ability of CM-HCECs in vivo. Slit-lamp microscopy and OCT showed that the cells made the cornea transparent about 7 days after the injection. In contrast, the control group still had severe corneal opacity and stromal edema at 1 month after scraping the endothelium (Fig. 7a and b). Rejection reactions such as keratic precipitates (KP) and anterior chamber exudation were noticed days 10 to 14 after the injection, but an almost normal cornea and anterior chamber could be seen after the postoperative treatment (Additional file 3: Figure S3). One month after the surgery, the corneas of the CM-HCEC group became more transparent and thinner. On the contrary, the corneal opacity and stromal edema became more serious in the control group (Fig. 7a and b). CM-HCECs created a polygonal monolayer with a cell density of about 2500 cells $/ \mathrm{mm}^{2}$. However, the corneal endothelium could not be clearly detected with specular microscopy or confocal microscopy in the control group because of the corneal opacity and edema (Fig. $7 \mathrm{a}-\mathrm{C}$ ). The CCT of the CMHCEC group was much thinner than that of the control group after surgery, and almost the same as that in normal corneas (Fig. 7d). Intraocular pressures (IOP) were 


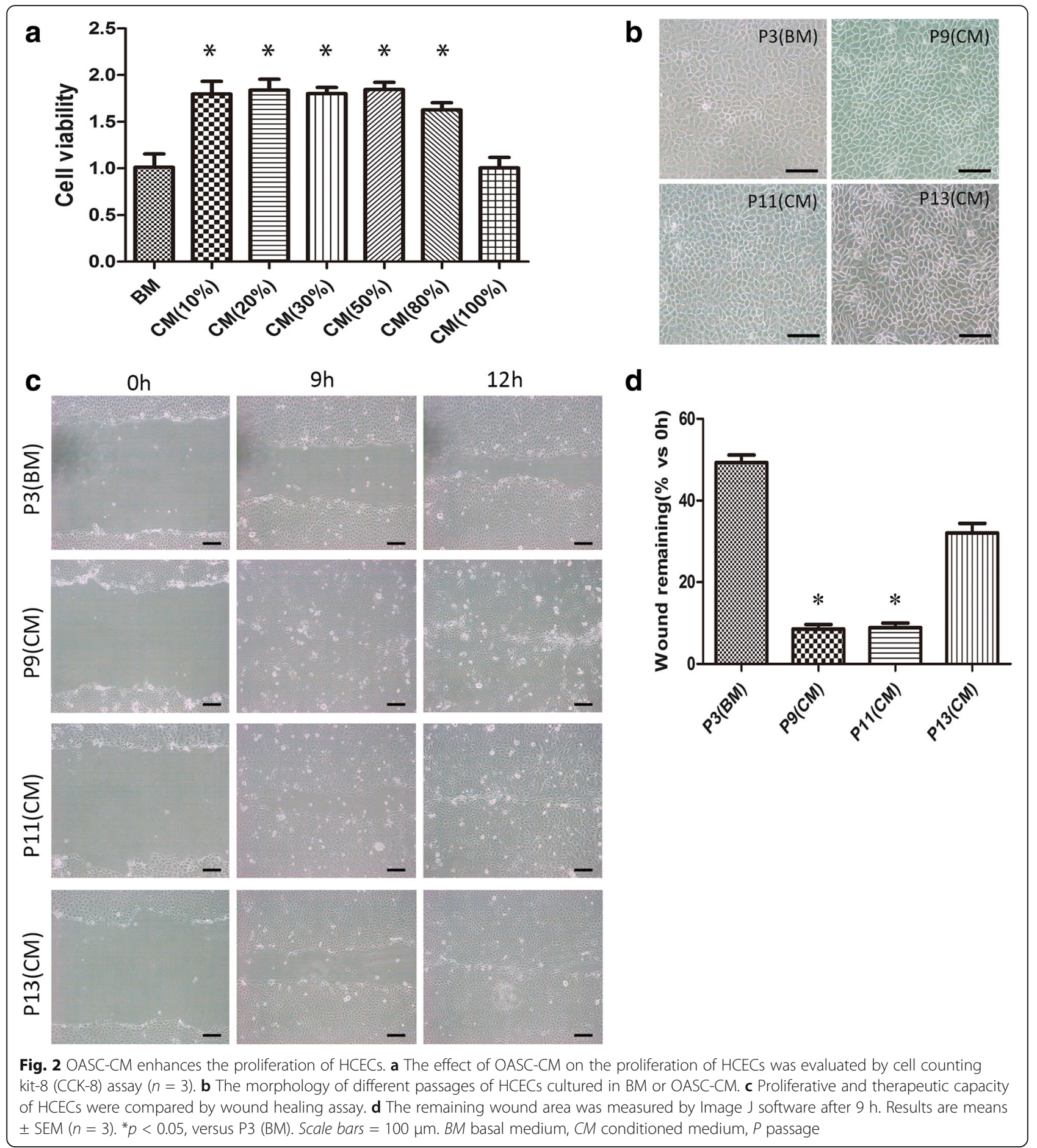

found to be no different between the CM-HCEC group and normal group (Fig. 7e).

The monkey models were observed for 10 months to evaluate the long-term effects of the HCEC injection. The corneas of the CM-HCEC group were still as transparent as normal cornea, while corneal opacity and stromal edema were obvious in the control group (Fig. 8a and c). The CECs showed a mosaic pattern with a cell density of about 3400 cells $/ \mathrm{mm}^{2}$ (Fig. 8b). A gonioscope, fundus photography, and B-mode ultrasound showed no pathological changes in the CM-HCEC eyes (Fig. 8d-g). Immunofluorescent staining showed CFSE-positive signals of HCECs and positive fluorescent staining of the nuclei 2 months after the cell injection, which demonstrated that the injected HCECs regenerated the corneal endothelium (Fig. $8 \mathrm{~h}-\mathrm{j}$ ). $\mathrm{Na}^{+} / \mathrm{K}^{+}$ ATPase and Zo-1 were also expressed in HCECs, indicating 


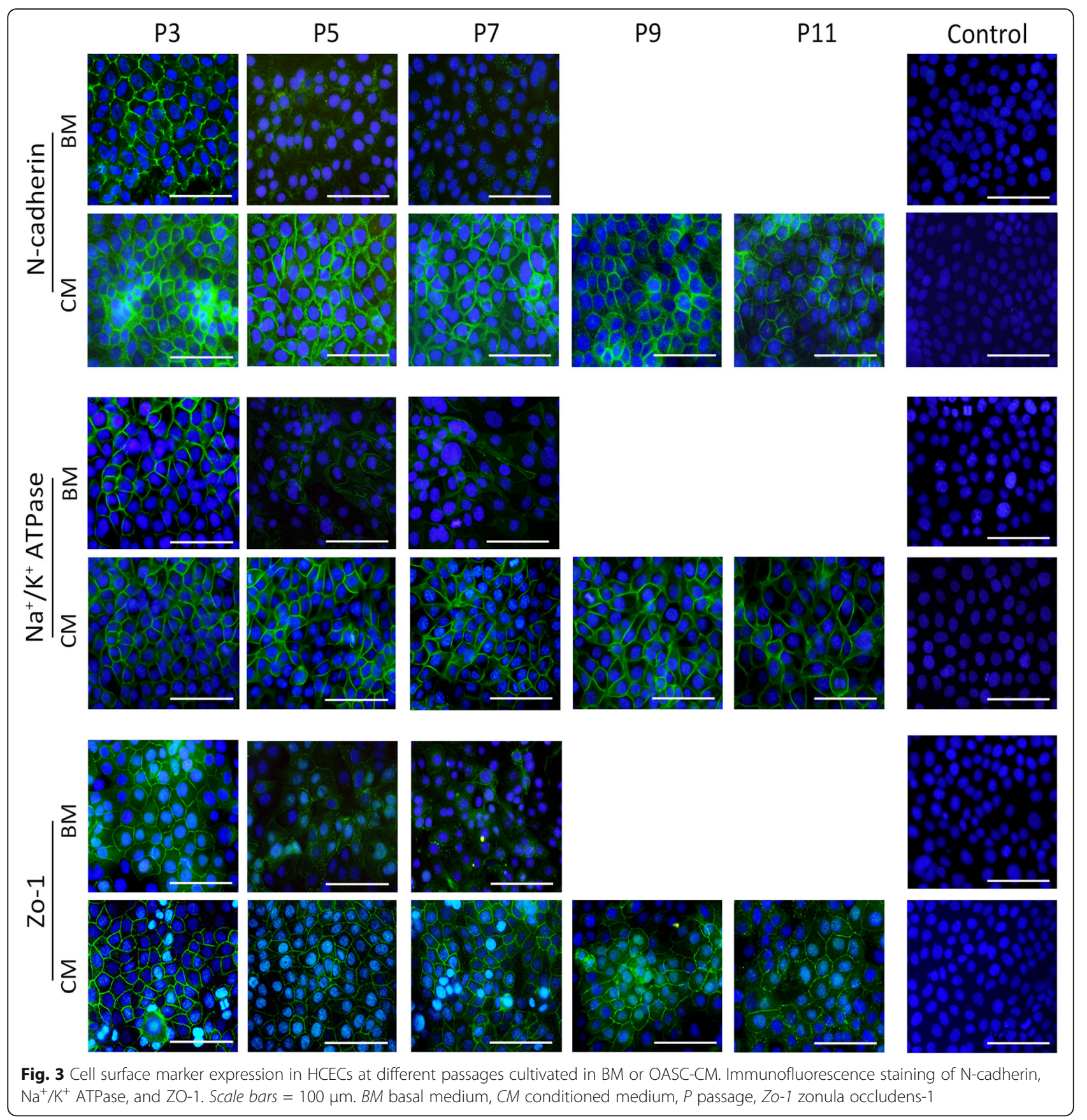

the persistent pump and barrier function (Fig. 8h and i). H\&E staining showed that the HCECs formed a monolayer on the DM (Fig. 8k). Immunohistochemical staining showed that no apparent human cells were found in other organs of the postoperative animals (Additional file 4: Figure S4). In addition, no obvious abnormalities were found in organs by H\&E staining (Additional file 5: Figure S5).

\section{Discussion}

As a major cause of corneal-related blindness, corneal endothelial dysfunction causes great damage to the visual acuity of a patient $[6,26]$. Corneal transplantation is still the only effective treatment for this disease. In recent years, some new procedures such as Descemet's stripping endothelial keratoplasty (DSEK), Descemet's stripping automated endothelial keratoplasty (DSAEK), and Descemet's membrane endothelial keratoplasty (DMEK) have been developed [6, 27-29]. Doctors and patients may have more choice and may even achieve better results. However, these methods face some obstacles such as their technical difficulty, continuing cell loss and detached lamellae after the operation, and graft rejections [30-32]. In 


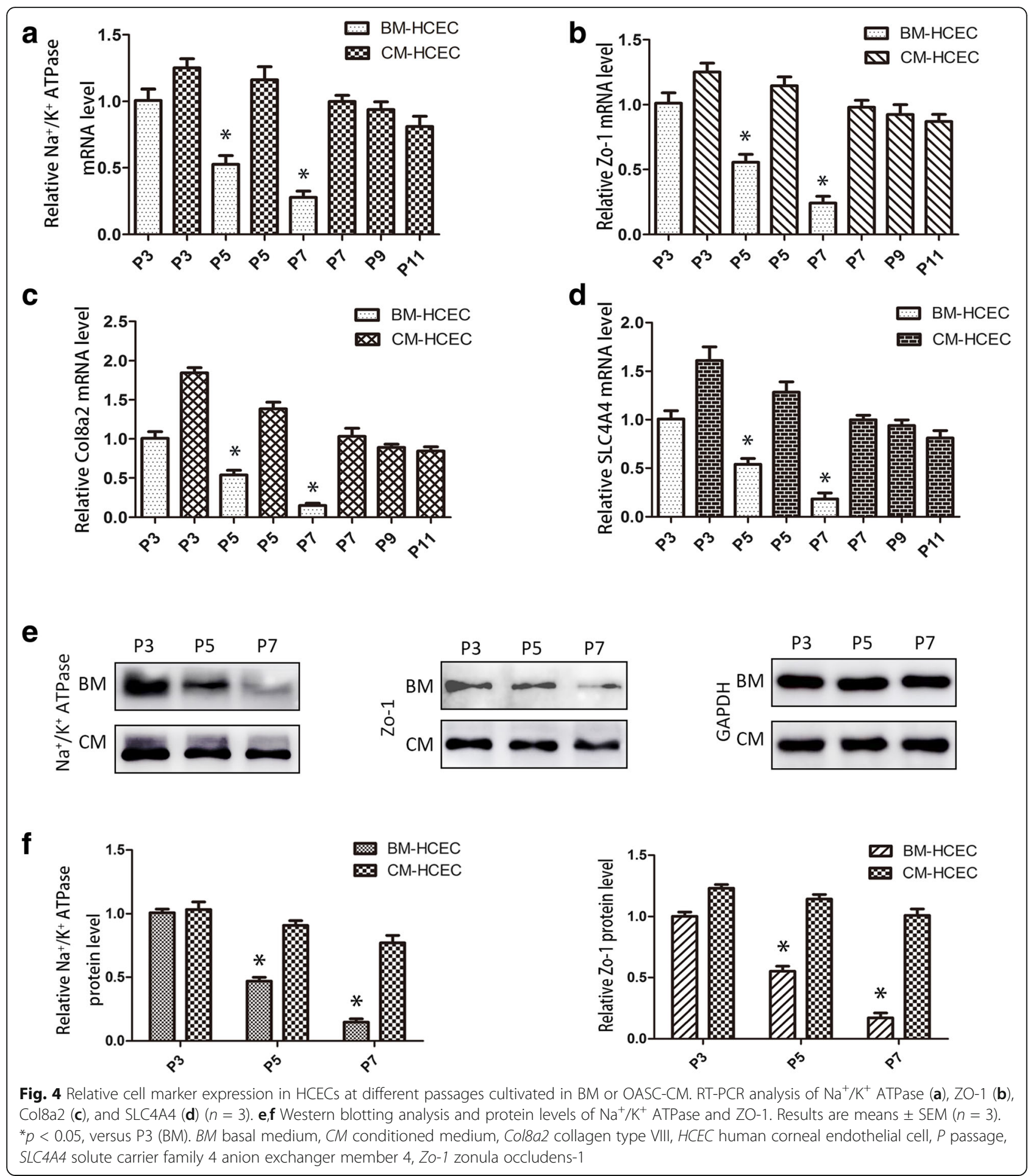

addition, the worldwide shortage of donor corneas is a particularly large problem. Thus the concept of using one donor cornea for treating one patient is already obsolete because of the rapid development in regenerative medicine and tissue engineering [9]. Regardless of the treatments, the importance of sufficient quantities of functional HCECs is self-evident. However, it is difficult to establish the optimum method for isolation and cultivation of HCECs in vitro.

Thus, many researchers including us have explored using other cells, such as neural crest cells (NCCs) [11], embryonic stem cells (ESCs) [10, 33], adipose-derived stem cells (ADSCs) [34], bone marrow-derived endothelial progenitor cells [35], umbilical cord blood-derived 


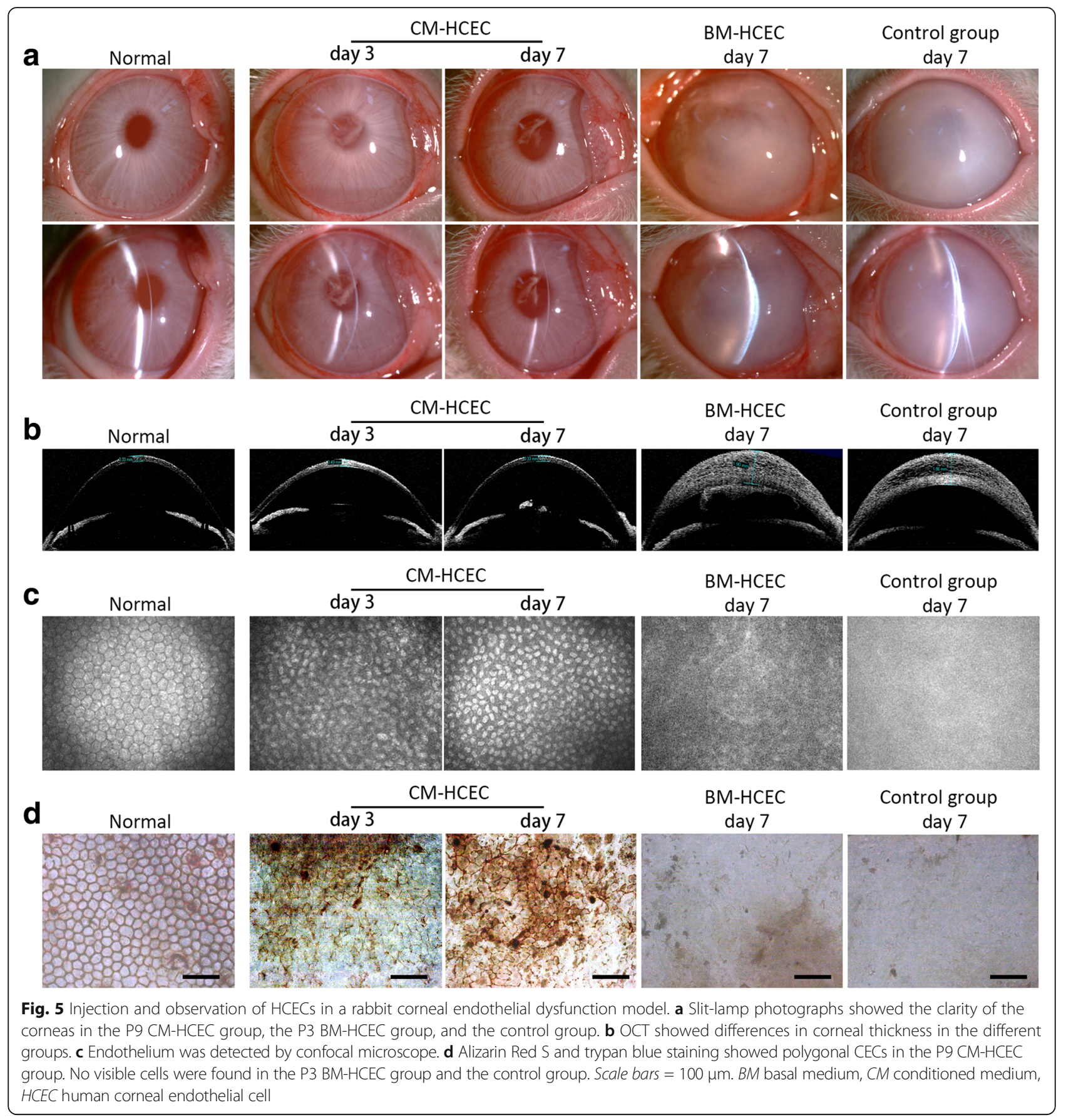

mesenchymal stem cells (UCB-MSCs) [12], corneal stroma stem cells [36], and skin-derived precursors (SKPs) [37], as CEC-like cells. These CEC-like cells have similar shapes and some characteristics of native HCECs. However, the limitations of the proliferation ability, pump and barrier function, ethical issues, or lack of preclinical studies impedes the potential therapy in clinical applications of these introduced CECs-like cells $[38,39]$. Therefore, the focus is still on how to improve proliferation and function of HCECs.
Recently, Nakahara et al. reported that HCEC expansion could be promoted by a conditioned medium obtained from human bone marrow-derived mesenchymal stem cells (BM-MSCs) [40]. An inhibitor to the transforming growth factor-beta receptor and a ROCK inhibitor also have beneficial effects on the expansion of HCECs [14, 41-43]. Kim and colleagues also compared the effects of different media on HCECs and attempted to find the optimum one [44]. However, we are still faced with difficulties with HCECs, such as the limited 


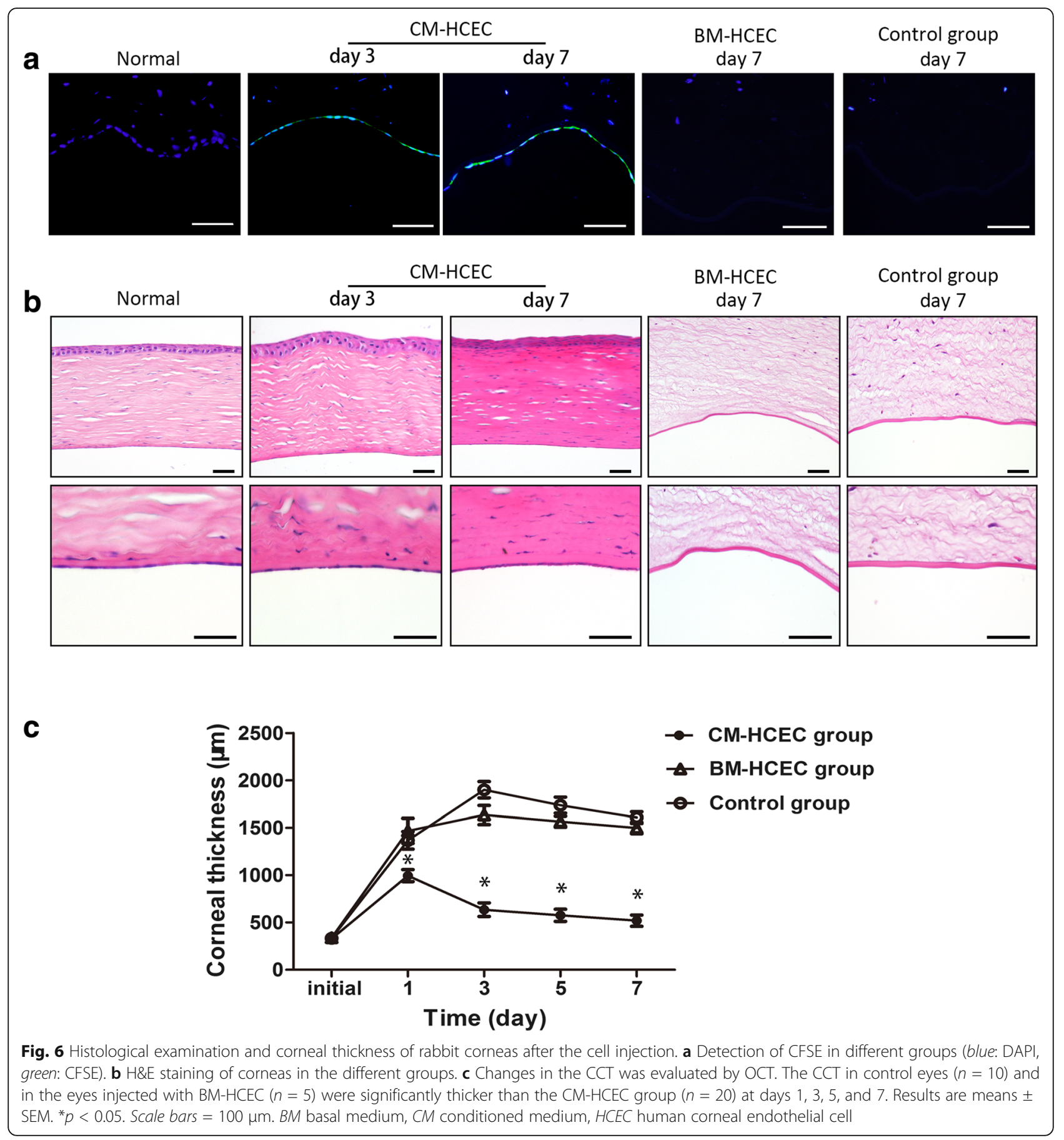

proliferative capacity and EMT with loss of function after a few passages [8, 45-47].

OASCs are derived from neural crest cells of the neuroectoderm [48, 49]. They possess a powerful proliferative capacity and multilineage differentiation potential, as do many other stem cells [18]. OASCs can be subcultured several times while maintaining the characteristics of stem cells. In addition, OASCs share the same embryonic origin with CECs [48]. We hypothesized that human OASCs could promote the expansion and function of HCECs while maintaining their phenotype. Besides, orbital adipose tissues are easily accessible and they provide huge numbers of stem cells [50]. We isolated HCECs and cultivated them with OASC-CM. The results of in vitro experiments showed that CM-HCECs have a polygonal shape similar to corneal endothelial cells in vivo, display an increased proliferative capacity, and highly express CEC-relative markers (N-cadherin, 


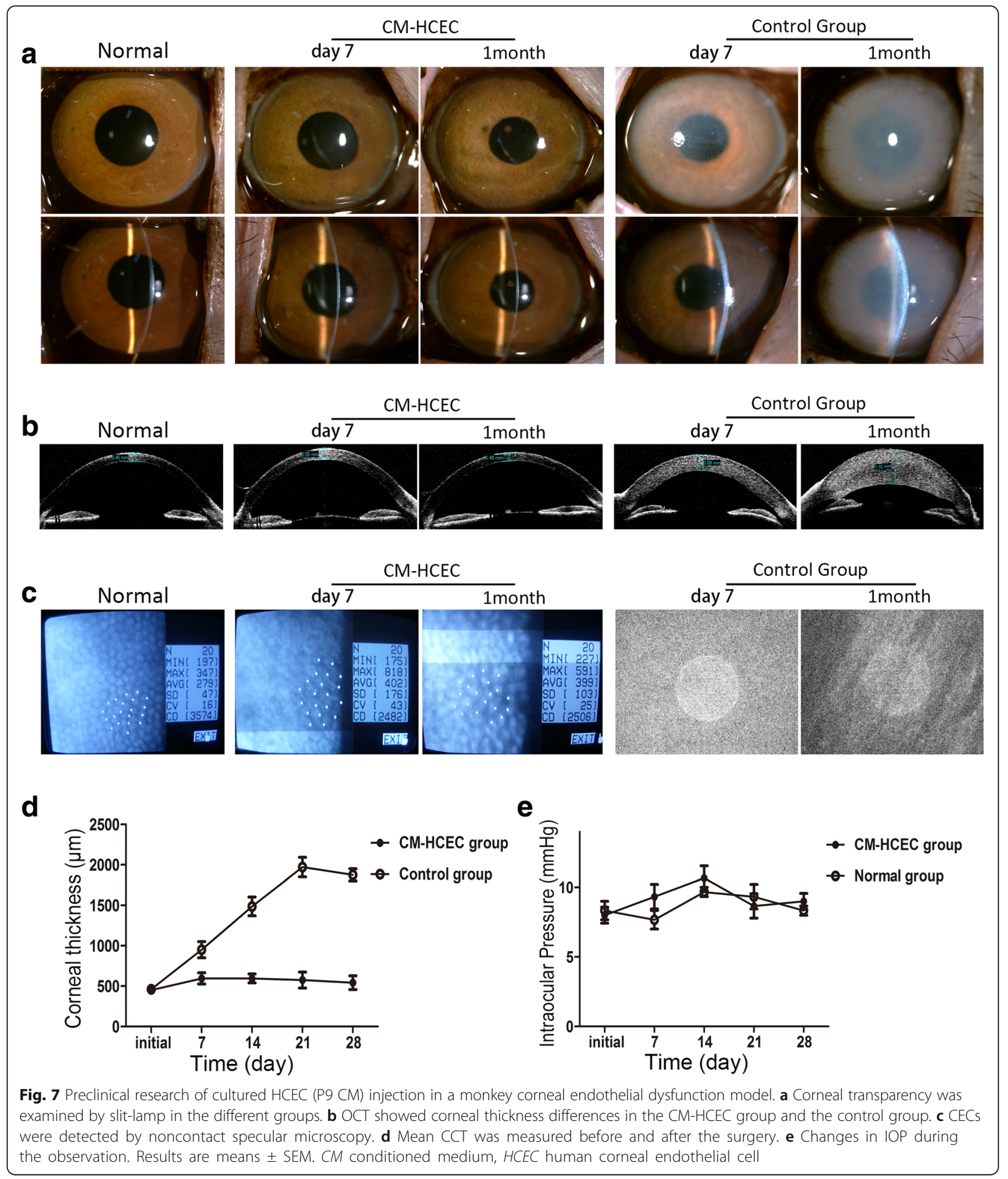

$\mathrm{Na}^{+} / \mathrm{K}^{+}$ATPase, ZO-1, Col8a2, and SLC4A4) even after 10 passages. In order to evaluate the repair capacity of the cultured HCECs we conducted experimental cell injection into a rabbit corneal endothelial dysfunction model. The results showed that the cornea could obtain clarity within 7 days. However, the rabbit CECs have proliferative ability [51, 52]. Corneal transparency may be the result of the combined action between injected cells and residual host CECs from the far peripheral cornea even though almost 
a

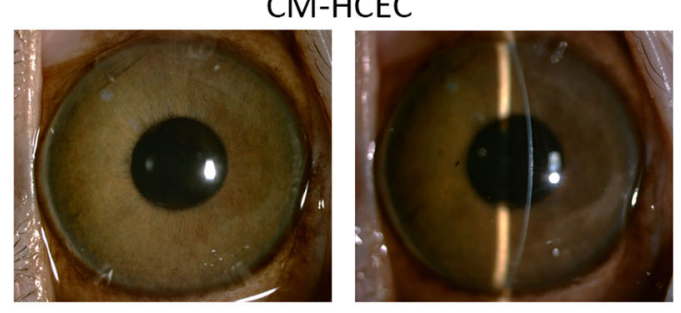

Control Group

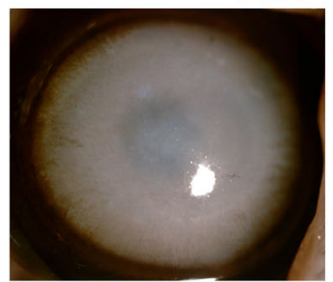

d

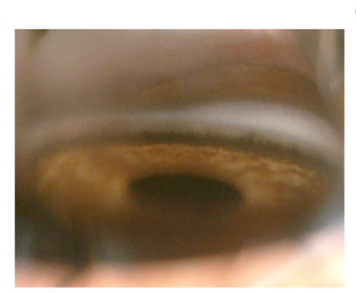

h

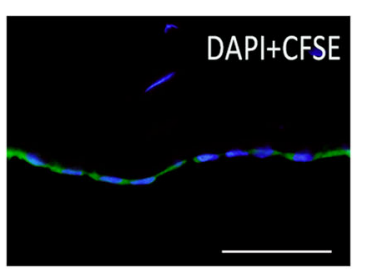

j

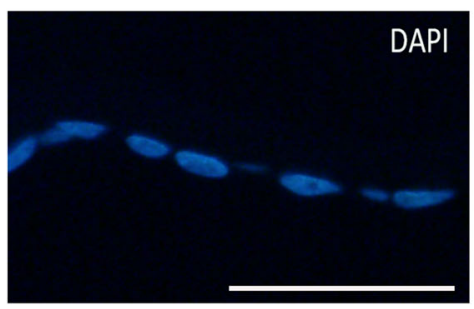

k

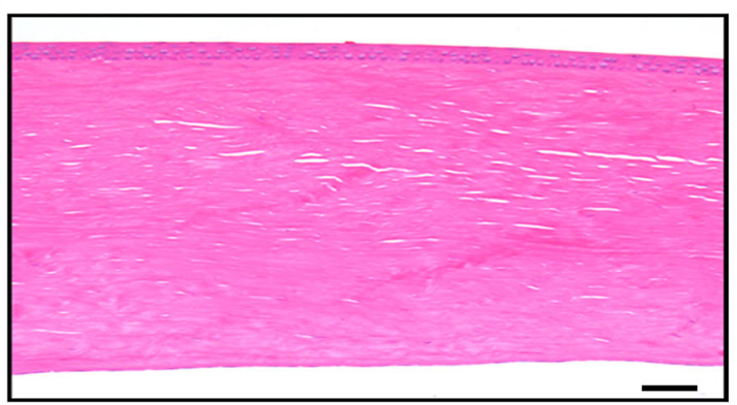

b

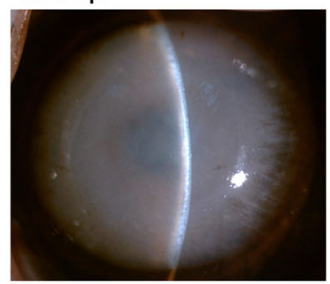

e

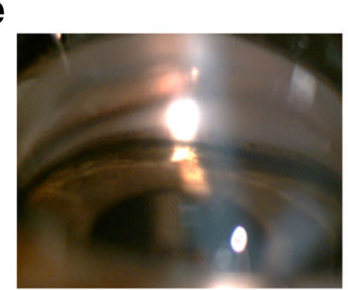

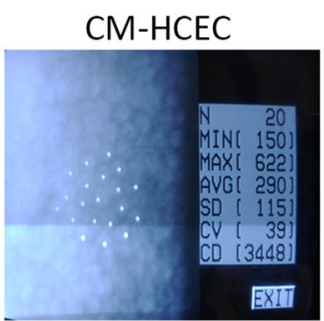

f

$$
\text { Control Group }
$$
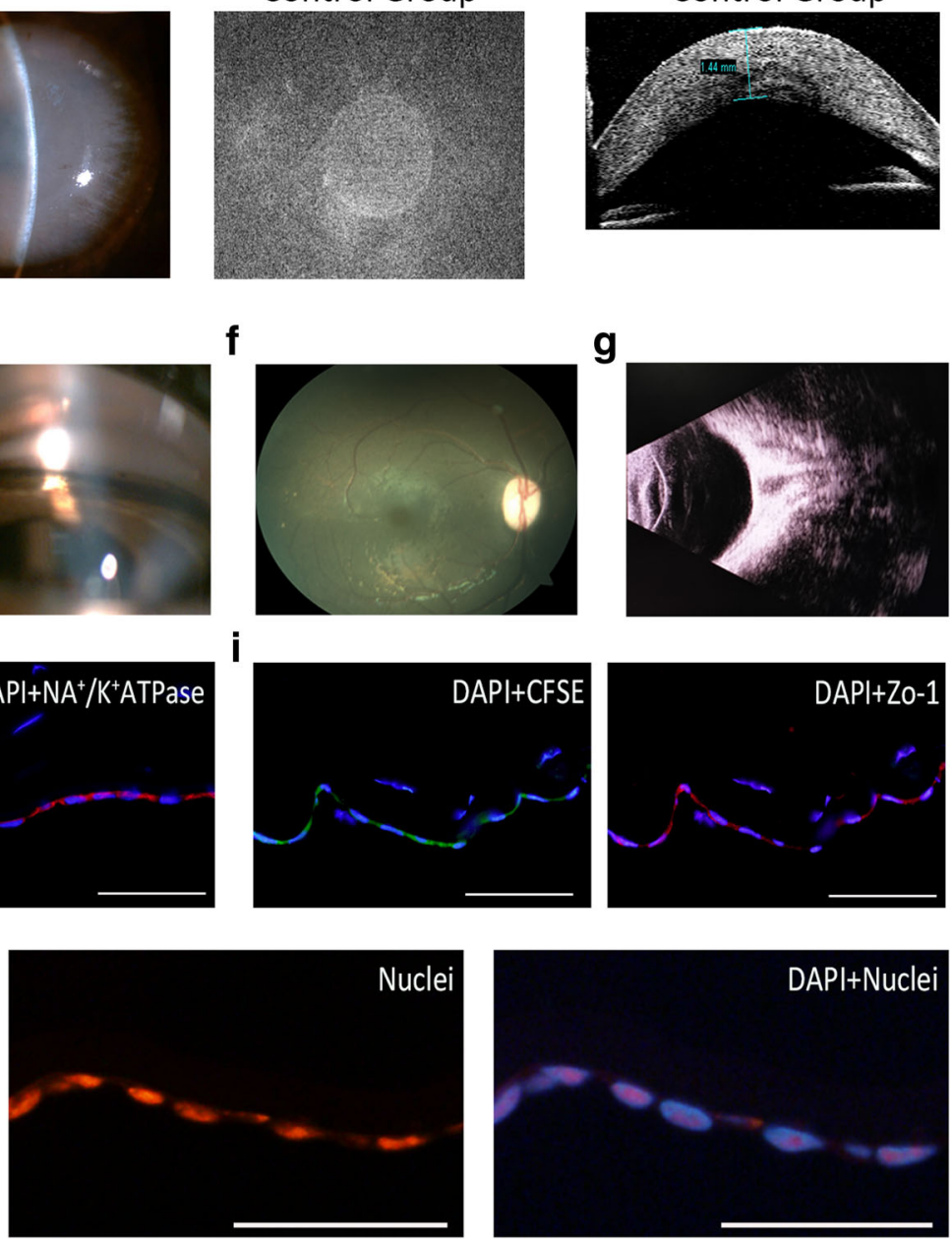

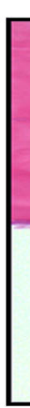
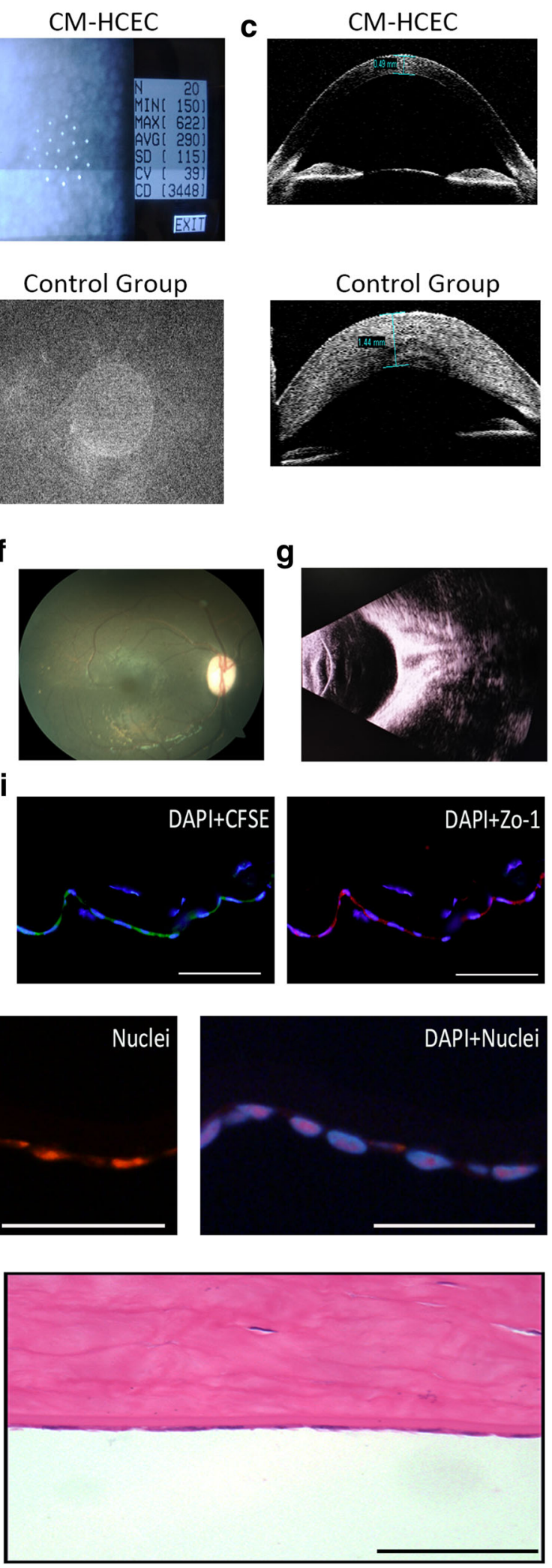

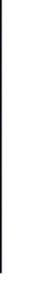


(See figure on previous page.)

Fig. 8 Long-term observation after CM-HCEC (P11) injection in the monkey model. a Corneal transparency was examined by slit-lamp in CM-HCEC group and control group. $\mathbf{b}$ CECs were detected by noncontact specular microscopy. $\mathbf{c}$ Corneal thickness differences in the CM-HCEC group and the control group by OCT. Angle images in the normal group (d) and the CM-HCEC group (e). f Fundus photography in the CM-HCEC group. $\mathbf{g}$ B-mode ultrasound in the CM-HCEC group. $\mathbf{h}$ Immunofluorescent staining of $\mathrm{Na}^{+} / \mathrm{K}^{+}$ATPase (blue: DAPI, green: CFSE, red: $\mathrm{Na}^{+} / \mathrm{K}^{+}$ATPase). i Immunofluorescent staining of Zo-1 (blue: DAPI, green: CFSE, red: Zo-1). $\mathbf{j}$ Immunofluorescent staining of nuclei (blue: DAPI, red: nuclei). $\mathbf{k}$ H\&E staining of cornea in the CMHCEC group. Images $(\mathbf{a}-\mathbf{g})$ were obtained 10 months after injection. Images $(\mathbf{h}-\mathbf{k})$ were obtained 2 months after injection. Scale bars $=100 \mu \mathrm{m}$. CFSE carboxyfluorescein succinmidyl ester, CM conditioned medium, HCEC human corneal endothelial cell, Zo-1 zonula occudens-1

all of the rabbit CECs were removed before the cell injection.

Literature reports that the monkey cornea is covered by migration of the remaining CECs when the corneal endothelium is injured, much like humans $[5,53,54]$. On the basis of the rabbit experiments we used a monkey model for further study aiming to eliminate the influence of proliferative CECs. The result of the primate experiment proved that the injection of CM-HCECs could well recover and maintain corneal transparency in corneal endothelial dysfunction models. Immunofluorescence and histological examination showed that CMHCECs could form a monolayer of polygonal cells and regenerate functional corneal endothelium. After 10 months of postoperative observation, the corneas were still transparent and maintained the normal corneal thickness in the CM-HCEC group, while the corneas remained severely edemic in the control group. All the results of the present study indicated that HCECs cultivated with OASC-CM in vitro had good proliferative and therapeutic capacity in vivo.

Theoretically, if HCECs are isolated from one donor cornea and cultivated as P0 with OASC-CM, we can obtain about $7 \times 10^{5}$ HCECs when they become confluent. When the cells are subcultured for 10 passages (passaged at a 1:2 ratio), the magnitude of HCECs would be $7 \times 10^{8}$, and then 2500 eyes could be injected (each eye needs $2.7 \times 10^{5}$ HCECs). These are encouraging prospects for clinical application.

The exact mechanisms of OASC-CM in promoting the proliferative and repair capacity of HCECs are not so clear. We hypothesize that the results are due to cytokines secreted by OASCs such as epidermal growth factor (EGF), basic fibroblasts growth factor (BFGF), and nerve growth factor (BGF). The HCECs then obtain some stem cell-like properties by using OASC-CM. This is one issue on which we should focus. Although corneal transparency recovered without adverse effects (secondary glaucoma or aberrant ectopic cell transplantation) in this study, episodes of immune rejection in some animals have been seen such as keratic precipitate (KP) and anterior chamber effusion after the cell injection; however, these are moderate and could be controlled by conventional therapy. The cause may be heterologous grafts, use of serum-containing medium, and nonadherent cells.
This is another issue with which we should deal. Since we have a mature technological process for fabricating scaffold materials [55-58], we will explore cultivating HCECs with serum-free medium and seeding them in the scaffold materials to construct a lamellar or full thickness tissue-engineered corneal substitute which may have good prospects in future clinical applications.

\section{Conclusions}

Use of the OASC-CM not only stimulates the proliferation of HCECs in vitro but also effectively promotes their repair capacity. We produced rabbit and monkey corneal endothelial dysfunction models and successfully treated them through cell injection. With this approach many more functional HCECs could be available for research and cell-based therapy for corneal endothelial dysfunction.

\section{Additional files}

Additional file 1: Figure S1. Cultured HCEC injection in the corneal endothelial dysfunction model and detection of residual cells in collected aqueous of rabbits and monkeys. (A) Schema of the cell injection into anterior chamber. (1) Scrape of endothelium on DM. (2) Injection of cultured HCECs into the anterior chamber. (3) The animals were kept in the face-down position for $5 \mathrm{~h}$ to allow the HCECs to sink to the DM of the cornea. $(C, D)$ The corneal endothelium was completely scraped from the DM (central and peripheral) of the rabbit model ( $\mathrm{C} 1$ and 2) and monkey model (D1 and 2) with a modified irrigator needle (B). (C3 and D3) HCECs suspended in MEM were injected into the anterior chamber with an insulin needle. (E) Aqueous were stained by trypan blue and hematoxylin to detect residual cells. (F) Aqueous were cultured in 96-well plates. Scale bar $=50 \mu \mathrm{m}$. (TIF $5105 \mathrm{~kb}$ )

Additional file 2: Figure S2. Cultured HCEC (P5 BM and P5 CM) injection in a rabbit corneal endothelial dysfunction model. More eye drops (six times a day) and subconjuctival injection (every 2 days) of dexamethasone were given after surgery. The corneal transparency and thickness were observed and photographed by slit-lamp microscopy and OCT. (TIF $1784 \mathrm{~kb}$ )

Additional file 3: Figure S3. Cultured HCEC injection in a monkey corneal endothelial dysfunction model. Slit-lamp photographs showed the monkey corneal endothelial dysfunction model (left). Slit-lamp photographs showed the monkey corneal endothelial dysfunction model following injection of P11 CM-HCECs (right). Images were obtained at days 14 and 21 and months 2, 4, and 6 after surgery. (TIF $2490 \mathrm{~kb}$ )

Additional file 4: Figure S4. Immunohistochemical analysis of rabbit and monkey organs after surgery. (A) Immunohistochemical staining of human nuclei in rabbit organs. (B) Immunohistochemical staining of human nuclei in monkey organs. (TIF $7183 \mathrm{~kb}$ )

Additional file 5: Figure S5. H\&E staining of monkey organs after the HCEC injection. Scale bar $=100 \mu \mathrm{m}$. (TIF $6389 \mathrm{~kb}$ ) 


\section{Abbreviations}

ADSC: Adipose-derived stem cell; APC: Allophycocyanin; BM: Basal culture medium; BM-MSC: Bone marrow-derived mesenchymal stem cell; CCK-8: Cell counting kit-8; CE: Corneal endothelium; CEC: Corneal endothelial cell; CFSE: Carboxyfluorescein diacetate succinimdyl ester; CM: Conditioned medium; DM: Descemet's membranes; DMEK: Descemet's membrane endothelial keratoplasty; DMEM-LG: Dulbecco's modified Eagle's medium low glucose; DSAEK: Descemet's stripping automated endothelial keratoplasty; DSEK: Descemet's stripping endothelial keratoplasty; EMT: Endothelial-tomesenchymal transition; ESC: Embryonic stem cell; FBS: Fetal bovine serum; FITC: Fluorescein isothiocyanate; H\&E: Hematoxylin and eosin; HCEC: Human corneal endothelial cell; hEGF: Human epidermal growth factor; KP: Keratic precipitates; NCC: Neural crest cell; OASC: Orbital adipose-derived stem cell; OCT: Optical coherent tomography; PBS: Phosphate-buffered saline; PE: Phycoerythrin; qRT-PCR: Quantitative real-time reverse transcription polymerase chain reaction; RT: Room temperature; SKP: Skin-derived precursor; UCB-MSC: Umbilical cord blood-derived mesenchymal stem cell; ZO1: Zonula occludens-1

\section{Acknowledgments}

The authors would like to thank Dr. Edward C. Mignot, Shandong University, for linguistic advice.

\section{Funding}

This work was supported by the Key Scientific and Technological Project of Shandong Province, People's Republic of China (2015GSF118018), and the National Natural Science Fund of China (81271716).

\section{Availability of data and materials}

The datasets used and/or analyzed during the current study are available from the corresponding author on reasonable request.

\section{Authors' contributions}

PS and XW were responsible for conception and design. PS, LS, and CZ cultured OASCs and HCECS. PS, LS, and LD performed the animal experiment $P S, L S, C Z$, and LD were responsible for assembly of data, and data analysis and interpretation. PS and LS were responsible for manuscript writing. PS and XW were responsible for revision of the manuscript. XW was responsible for provision of study material. All authors read and approved the final manuscript.

\section{Ethics approval and consent to participate}

All animals were treated in accordance with the ARVO (Association for Research in Vision and Ophthalmology) Statement for the Use of Animals in Ophthalmic and Vision Research. All animal experiments were approved by the Medical Ethics Committee of Qilu Hospital of Shandong University, China. Samples were collected following written informed consents, and the study was performed in adherence to the Declaration of Helsinki. All the experimental protocols were approved by the Ethical Committee of Qilu Hospital of Shandong University and were conducted following the institutional guidelines

\section{Consent for publication}

Not applicable.

\section{Competing interests}

The authors declare that they have no competing interests.

\section{Publisher's Note}

Springer Nature remains neutral with regard to jurisdictional claims in published maps and institutional affiliations.

\section{Author details}

'Department of Ophthalmology, Qilu Hospital of Shandong University, Jinan, Shandong 250012, People's Republic of China. ${ }^{2}$ The Key Laboratory of Cardiovascular Remodeling and Function Research, Chinese Ministry of Education and Chinese Ministry of Health, Qilu Hospital of Shandong University, Jinan, Shandong 250012, People's Republic of China.
Received: 3 October 2017 Revised: 16 November 2017

Accepted: 28 November 2017 Published online: 20 December 2017

\section{References}

1. Bourne WM. Clinical estimation of corneal endothelial pump function. Trans Am Ophthalmol Soc. 1998;96:229-39. discussion 239-42.

2. Joyce NC. Proliferative capacity of the corneal endothelium. Prog Retin Eye Res. 2003;22:359-89.

3. Senoo $T$, Joyce NC. Cell cycle kinetics in corneal endothelium from old and young donors. Invest Ophthalmol Vis Sci. 2000;41:660-7.

4. Joyce NC, Harris DL, Mello DM. Mechanisms of mitotic inhibition in corneal endothelium: contact inhibition and TGF-beta2. Invest Ophthalmol Vis Sci. 2002;43:2152-9.

5. Joyce NC. Proliferative capacity of corneal endothelial cells. Exp Eye Res. 2012;95:16-23

6. Tan DT, Dart JK, Holland EJ, Kinoshita S. Corneal transplantation. Lancet. 2012;379:1749-61.

7. Van den Bogerd B, SN Dhubhghaill, C Koppen, MJ Tassignon and N Zakaria. A review of the evidence for in vivo corneal endothelial regeneration. Surv Ophthalmol. 2017; doi: 10.1016/j.survophthal.2017.07.0041. [Epub ahead of print]

8. Peh GS, Beuerman RW, Colman A, Tan DT, Mehta JS. Human corneal endothelial cell expansion for corneal endothelium transplantation: an overview. Transplantation. 2011:91:811-9.

9. Mimura T, Yamagami S, Amano S. Corneal endothelial regeneration and tissue engineering. Prog Retin Eye Res. 2013;35:1-17.

10. Zhang K, Pang K, Wu X. Isolation and transplantation of corneal endothelial cell-like cells derived from in-vitro-differentiated human embryonic stem cells. Stem Cells Dev. 2014;23:1340-54.

11. Ju C, Zhang K, Wu X. Derivation of corneal endothelial cell-like cells from rat neural crest cells in vitro. PLoS One. 2012;7:e42378.

12. Joyce NC, Harris DL, Markov V, Zhang Z, Saitta B. Potential of human umbilical cord blood mesenchymal stem cells to heal damaged corneal endothelium. Mol Vis. 2012;18:547-64.

13. Zhu C, Joyce NC. Proliferative response of corneal endothelial cells from young and older donors. Invest Ophthalmol Vis Sci. 2004;45:1743-51.

14. Okumura N, Kay EP, Nakahara M, Hamuro J, Kinoshita S, Koizumi N. Inhibition of TGF-beta signaling enables human corneal endothelial cell expansion in vitro for use in regenerative medicine. PLoS One. 2013;8: e58000.

15. Moysidis SN, Alvarez-Delfin K, Peschansky VJ, Salero E, Weisman AD, Bartakova A, Raffa GA, Merkhofer Jr RM, Kador KE, Kunzevitzky NJ, Goldberg JL. Magnetic field-guided cell delivery with nanoparticle-loaded human corneal endothelial cells. Nanomedicine. 2015;11:499-509.

16. Polisetti N, Joyce NC. The culture of limbal stromal cells and corneal endothelial cells. Methods Mol Biol. 2013;1014:131-9.

17. Kang HM, Kim J, Park S, Kim J, Kim H, Kim KS, Lee EJ, Seo SI, Kang SG, Lee JE, Lim H. Insulin-secreting cells from human eyelid-derived stem cells alleviate type I diabetes in immunocompetent mice. Stem Cells. 2009;27: 1999-2008.

18. Ho JH, Ma WH, Tseng TC, Chen YF, Chen MH, Lee OK. Isolation and characterization of multi-potent stem cells from human orbital fat tissues. Tissue Eng Part A. 2011;17:255-66.

19. Mimura T, Joyce NC. Replication competence and senescence in centra and peripheral human corneal endothelium. Invest Ophthalmol Vis Sci. 2006:47:1387-96.

20. Koizumi N, Sakamoto Y, Okumura N, Okahara N, Tsuchiya H, Torii R, Cooper LJ, Ban Y, Tanioka H, Kinoshita S. Cultivated corneal endothelial cell sheet transplantation in a primate model. Invest Ophthalmol Vis Sci. 2007:48:4519-26.

21. Okumura N, Koizumi N, Ueno M, Sakamoto Y, Takahashi H, Tsuchiya H, Hamuro J, Kinoshita S. ROCK inhibitor converts corneal endothelial cells into phenotype capable of regenerating in vivo endothelial tissue. Am J Pathol. 2012;181:268-77.

22. Risen LA, Binder $P$, Noyok S. Intermediate filaments and their organization in human corneal endothelium. Inves Ophthalmol Vis Sci. 1987:28:1933-8

23. Reneker LW, Silversides DW, Xu L, Overbeek PA. Formation of corneal endothelium is essential for anterior segment development-a transgenic mouse model of anterior segment dysgenesis. Development. 2000;127:533-42. 
24. Sha X, Liu Z, Song L, Wang Z, Liang X. Human amniotic epithelial cell niche enhances the functional properties of human corneal endothelial cells via inhibiting P53-survivin-mitochondria axis. Exp Eye Res. 2013;116:36-46.

25. Lachaud CC, Soria F, Escacena N, Quesada-Hernandez E, Hmadcha A, Alio J, Soria B. Mesothelial cells: a cellular surrogate for tissue engineering of corneal endothelium. Invest Ophthalmol Vis Sci. 2014;55:5967-78.

26. Whitcher JP, Srinivasan M, Upadhyay MP. Corneal blindness: a global perspective. Bull World Health Organ. 2001;79:214-21.

27. Price Jr FW, Feng MT, Price MO. Evolution of endothelial keratoplasty: where are we headed? Cornea. 2015;34 Suppl 10:541-7.

28. Melles GR, Ong TS, Ververs B, van der Wees J. Preliminary clinical results of Descemet membrane endothelial keratoplasty. Am J Ophthalmol. 2008;145:222-7.

29. Tong CM, Baydoun L, Melles GRJ. Descemet membrane endothelial keratoplasty and refractive surgery. Curr Opin Ophthalmol. 2017;28:316-25.

30. Terry MA, Chen ES, Shamie N, Hoar KL, Friend DJ. Endothelial cell loss after Descemet's stripping endothelial keratoplasty in a large prospective series. Ophthalmology. 2008;115:488-96. e3.

31. Mehta JS, Chua J, Poh R, Beuerman RW, Tan D. Primary graft failure after Descemet-stripping automated endothelial keratoplasty: clinico-pathological study. Cornea. 2008;27:722-6.

32. Lehman RE, Copeland LA, Stock EM, Fulcher SF. Graft detachment rate in DSEKJDSAEK after same-day complete air removal. Cornea. 2015;34:1358-61.

33. Song Q, Yuan S, An Q, Chen Y, Mao FF, Liu Y, Liu Q, Fan G. Directed differentiation of human embryonic stem cells to corneal endothelial celllike cells: a transcriptomic analysis. Exp Eye Res. 2016;151:107-14.

34. Dai Y, Guo Y, Wang C, Liu Q, Yang Y, Li S, Guo X, Lian R, Yu R, Liu H, Chen J. Non-genetic direct reprogramming and biomimetic platforms in a preliminary study for adipose-derived stem cells into corneal endothelia-like cells. PLoS One. 2014;9:e109856.

35. Shao C, Fu Y, Lu W, Fan X. Bone marrow-derived endothelial progenitor cells: a promising therapeutic alternative for corneal endothelial dysfunction. Cells Tissues Organs. 2011;193:253-63.

36. Hatou S, Yoshida S, Higa K, Miyashita H, Inagaki E, Okano H, Tsubota K, Shimmura S. Functional corneal endothelium derived from corneal stroma stem cells of neural crest origin by retinoic acid and Wnt/beta-catenin signaling. Stem Cells Dev. 2013;22:828-39.

37. Inagaki E, Hatou S, Higa K, Yoshida S, Shibata S, Okano H, Tsubota K, Shimmura S. Skin-derived precursors as a source of progenitors for corneal endothelial regeneration. Stem Cells Transl Med. 2017;6:788-98.

38. Yuan S, Fan G. Stem cell-based therapy of corneal epithelial and endothelial diseases. Regen Med. 2015;10:495-504.

39. Saghizadeh M, Kramerov AA, Svendsen CN, Ljubimov AV. Concise review: stem cells for corneal wound healing. Stem Cells. 2017;35(10):2105-14.

40. Nakahara M, Okumura N, Kay EP, Hagiya M, Imagawa K, Hosoda Y, Kinoshita S, Koizumi N. Corneal endothelial expansion promoted by human bone marrow mesenchymal stem cell-derived conditioned medium. PLoS One. 2013;8:e69009.

41. Zhu YT, Li F, Han B, Tighe S, Zhang S, Chen SY, Liu X, Tseng SC. Activation of RhoA-ROCK-BMP signaling reprograms adult human corneal endothelial cells. J Cell Biol. 2014;206:799-811.

42. Okumura N, Fujii K, Kagami T, Makiko N, Kitahara M, Kinoshita S, Koizumi N. Activation of the Rho/Rho kinase signaling pathway is involved in cell death of corneal endothelium. Invest Ophthalmol Vis Sci. 2016;57:6843-51.

43. Okumura N, Sakamoto Y, Fujii K, Kitano J, Nakano S, Tsujimoto Y, Nakamura S, Ueno M, Hagiya M, Hamuro J, Matsuyama A, Suzuki S, Shiina T, Kinoshita S. Koizumi N. Rho kinase inhibitor enables cell-based therapy for corneal endothelial dysfunction. Sci Rep. 2016;6:26113.

44. Kim E, Kim JJ, Hyon JY, Chung ES, Chung TY, Yi K, Wee WR, Shin YJ. The effects of different culture media on human corneal endothelial cells. Invest Ophthalmol Vis Sci. 2014;55:5099-108.

45. Senoo T, Obara Y, Joyce NC. EDTA: a promoter of proliferation in human corneal endothelium. Invest Ophthalmol Vis Sci. 2000;41:2930-5.

46. Lee JG, Ko MK, Kay EP. Endothelial mesenchymal transformation mediated by IL-1 beta-induced FGF-2 in corneal endothelial cells. Exp Eye Res. 2012;95:35-9.

47. Bartakova A, Alvarez-Delfin K, Weisman AD, Salero E, Raffa GA, Merkhofer J RM, Kunzevitzky NJ, Goldberg JL. Novel identity and functional markers for human corneal endothelial cells. Invest Ophthalmol Vis Sci. 2016;57:2749-62.

48. Crane JF, Trainor PA. Neural crest stem and progenitor cells. Annu Rev Cell Dev Biol. 2006;22:267-86.

49. Billon N, lannarelli P, Monteiro MC, Glavieux-Pardanaud C, Richardson WD, Kessaris N, Dani C, Dupin E. The generation of adipocytes by the neural crest. Development. 2007;134:2283-92.
50. Estes BT, Diekman BO, Gimble JM, Guilak F. Isolation of adipose-derived stem cells and their induction to a chondrogenic phenotype. Nat Protoc. 2010;5:1294-311.

51. Van Horn DL, Sendele DD, Seideman S, Buco PJ. Regenerative capacity of the corneal endothelium in rabbit and cat. Invest Ophthalmol Vis Sci. 1977;16:597-613.

52. Choi SO, Jeon HS, Hyon JY, Oh YJ, Wee WR, Chung TY, Shin YJ, Kim JW. Recovery of corneal endothelial cells from periphery after injury. PLoS One. 2015;10:e0138076.

53. Van Horn DL, Hyndiuk RA. Endothelial wound repair in primate cornea. Exp Eye Res. 1975;21:113-24.

54. Matsubara M, Tanishima T. Wound-healing of corneal endothelium in monkey: an autoradiographic study. Jpn J Ophthalmol. 1983;27:444-50.

55. Du L, Wu X, Pang K, Yang Y. Histological evaluation and biomechanical characterisation of an acellular porcine cornea scaffold. Br J Ophthalmol. 2011;95:410-4.

56. Pang K, Du L, Wu X. A rabbit anterior cornea replacement derived from acellular porcine cornea matrix, epithelial cells and keratocytes. Biomaterials. 2010;31:7257-65.

57. Zhu J, Zhang K, Sun Y, Gao X, Li Y, Chen Z, Wu X. Reconstruction of functional ocular surface by acellular porcine cornea matrix scaffold and limbal stem cells derived from human embryonic stem cells. Tissue Eng Part A. 2013;19:2412-25.

58. Zhang CW, Du LQ, Sun P, Shen L, Zhu J, Pang KP, Wu XY. Construction of tissue-engineered full-thickness cornea substitute using limbal epithelial cell-like and corneal endothelial cell-like cells derived from human embryonic stem cells. Biomaterials. 2017;124:180-94.

\section{Submit your next manuscript to BioMed Central and we will help you at every step:}

- We accept pre-submission inquiries

- Our selector tool helps you to find the most relevant journal

- We provide round the clock customer support

- Convenient online submission

- Thorough peer review

- Inclusion in PubMed and all major indexing services

- Maximum visibility for your research

Submit your manuscript at www.biomedcentral.com/submit
) Biomed Central 